\title{
VICENTE NÚÑEZ EN LOS MÁRGENES DEL CANON: DEL MEDIO SIGLO A LA POSTMODERNIDAD
}

\author{
VICENTE NÚÑEZ AI MARGINI DEL CANONE: \\ DAGLI ANNI CINQUANTA ALLA POSTMODERNITÀ
}

\author{
MARINA BIANCHI \\ Università degli Studi di Bergamo \\ marina.bianchi@unibg.it
}

Fecha de recepción: 02-12-2019

Fecha de aceptación: 06-05-2020

\section{RESUMEN}

Los versos de Vicente Núñez revelan sus inquietudes interiores, entre las que prima la congoja de herencia cernudiana por una sensualidad que no se ajusta a la moral franquista. Inicialmente cercano al grupo Cántico, por la fecha de sus primeras publicaciones pertenecería a la Generación del 50. Sin embargo, cuando vuelve a la literatura tras más de veinte años de ausencia, sus textos se cargan de elementos postmodernos: la mentira como juego retórico y tema metapoético, la expresión de un sujeto en crisis, el fragmentarismo, la voluntad de romper con el lenguaje tradicional y, aún más, la proximidad a la teoría queer y a sus planteamientos sobre la conformación de una identidad que supere la construcción cultural genérica impuesta. Núñez forja entonces un habla subversiva basada en el silencio, con el propósito de quebrantar los preconceptos y los dogmas, para proponer un nuevo paradigma interpretativo de la realidad y del sujeto mismo.

Palabras Clave: Vicente Núñez; poesía española contemporánea; canon; silencio; Postmodernidad; teoría queer

\section{RIASSUNTO}

I versi di Vicente Núñez rivelano le sue inquietudini interiori, tra le quali spicca l'eredità cernudiana dell'afflizione dovuta a una sensualità non conforme alla morale 
franchista. Inizialmente vicino al gruppo Cántico, la data delle sue prime pubblicazioni lo ricondurrebbe alla Generazione del '50. Tuttavia, quando riprende a scrivere dopo un allontanamento di oltre vent'anni, i suoi testi si colmano di elementi postmoderni: la menzogna come gioco retorico e tema metapoetico, l'espressione di un soggetto in crisi, il frammentarismo, la volontà di trasgredire il linguaggio tradizionale e, ancor più, la prossimità alla teoria queer e al suo progetto di formazione di un'identità che superi la costruzione culturale dei due generi imposti. Núñez crea quindi un discorso sovversivo basato sul silenzio, con il proposito di infrangere i preconcetti e i dogmi, al fine di proporre un nuovo paradigma interpretativo della realtà e del soggetto stesso.

Parole Chiave: Vicente Núñez; poesia spagnola contemporanea; canone; silenzio; Postmodernità; teoria queer

\section{BREVE PREMISA ${ }^{1}$}

Toda obra literaria siempre se modela como un producto cultural de un hic et nunc determinado, puesto que integra la configuración lingüística del texto, la influencia del contexto, la transmisión de conocimiento, la intencionalidad del autor y su personal visión e interpretación del mundo; a todo esto se suma la perspectiva del lector, quien también genera sentido en el ejercicio de su actividad. Por supuesto, nos referimos a las distintas ramas que conforman la actual teoría de la literatura; entre ellas: la estilística (SPITZER, 1931), la nueva retórica (Perelman y Olbrechts-Tyteca, 1958), la pragmática (Austin, 1962; SeArle, 1969), la semiología (Morris 1946; Lotman, 1976) y la semiótica (Kristeva, [1969] 1981; Greimas y Courtés 1979), la sociocrítica (Althusser, 1970), la estética de la recepción (IsER, 1974; JAUss, 1982), la hermenéutica (Eco, 1962 y 1979; RICOEUR 1984), y la teoría de los polisistemas (Even-ZOHAR, 1979).

Por otro lado, así como el legado de los predecesores influye en el código presente entendido como conjunto de unidades de significación, con sus reglas combinatorias y su estructura- y deja huellas en el contenido, ${ }^{2}$ cada obra necesita encontrar su lugar en el canon para volverse universal, para formar parte del lenguaje de la tradición para los escrito-

1 Este trabajo ha sido realizado durante la estancia en la UNED (Madrid), del 7 de mayo al 6 de junio de 2018, en el marco de las Ayudas Complementarias para el fomento de la movilidad e internacionalización del profesorado de la Facultad de Filología (Convocatoria 2018) y vinculada al Grupo de Investigación «Literatura y Canon» de la misma Facultad. Además, este artículo se halla vinculado al Proyecto de Investigación del Plan Estatal «Poéticas de la Transición (1973-1982)», financiado por FEDER/Ministerio de Ciencia, Innovación y Universidades - Agencia Estatal de Ivestigación/FFI2017-84759-P.

2 Como es sabido, toda obra literaria establece un diálogo constante con las demás, puesto que la auctoritas reside en lo antiguo revivido desde la visión actual, como recuperación de los textos consagrados de la historia de la literatura cuya resonancia ha contribuido a formar la individualidad del sujeto poético. En este sentido, los artistas progresan en el trayecto construido por sus predecesores, de acuerdo con las teorizaciones sobre el dialogismo, la dimensión social del lenguaje y la polifonía de Mijaíl Bajtín (2003: 15, 67-68 y 279-282), sobre el lenguaje ya nombrado y el código previo de Roland Barthes (2003: 17), y sobre la intertextualidad de Julia Kristeva (1981: 66-67); por ende, el poeta tiene que ser ante todo un buen lector, para luego arrojar nueva luz y sentido sobre lo heredado. 
res futuros, es decir, del código para la posteridad. De acuerdo con Yuri Lotman, esta ambición se relaciona con el hecho de que el arte es una forma de conocimiento (1978: 9-10) que supone y aspira a transmitir un modelo determinado del mundo (1978: 69).

\section{VICENTE NÚÑEZ Y LA POESÍA DEL MEDIO SIGLO}

Como ya se ha señalado (cfr. BiAnchI, 2016a: 47-65), Vicente Núñez (Aguilar de la Frontera, 1926 - 2002) no hace referencia al contexto histórico de la dictadura franquista en su producción literaria: tan solo describe la primera posguerra de forma explícita en una ocasión, evocando el desconcierto de la época. Recuerda que en aquel contexto social y cultural nada seguía en su lugar; sin embargo, aunque veremos que no es exactamente así, informa que la única consecuencia directa sobre su personalidad fue dejar que en la temporada oscura naciese la luz de la poesía (en CASADO, 2004: 72):

Era un caos la España de la posguerra inmediata. [...]. Un caos de todo, un caos de costumbres, pero también de chaquetas, de zapatos; cuando un caos se cierne planetariamente, es un caos total: la sintaxis se rompe, la sintaxis esencial, la cotidiana, la paternofilial, la del noviazgo... no se sabía de qué hablar, qué decir [...]. Era un desconcierto, los padres no sabían lo que era educar a un hijo, para qué servía la carrera, para qué lo mandaban a Madrid, si el dinero que se gastaban en ti tenía sentido...

$Y$ de ese caos nació la luminosidad de la poesía. Que nadie eduque a nadie, si quiere convertirlo en poeta desde la luz, desde la tiniebla.

Como es sabido, en 1976, Guillermo Carnero (1976: 15) resume en dos opuestas tendencias la poesía española de la posguerra: los que se acercan al compromiso social y político, y los que no lo hacen; si lo viéramos así, Núñez pertenecería al segundo grupo, junto con los redactores de la revista cordobesa Cántico. Aunque coloca a los poetas de Cántico entre las actitudes no comprometidas e incluye a Núñez en la nueva versión de 2009 de su antología, Carnero afirma que «no resulta propio esgrimir tal compromiso o postura contra otras actitudes literarias que no lo exhiben» (2009: 31), retomando luego una afirmación del mismo Núñez sobre Luis Cernuda para describirlo como: «poeta de la condición humana que no por ello se abandona a la gesticulación retórica ni al avulgaramiento del lenguaje» (2009: 130). Desde luego, como los miembros de Cántico, Núñez se aleja tanto de la monotonía de Garcilaso como del tremendismo de Espadaña; sin embargo, la disidencia en el medio siglo incorpora fórmulas de compromiso que, además de la poesía de la comunicación o Poesía Social, incluyen posturas más intimistas, relacionadas con las emociones que la situación histórica y privada suscita en el individuo. ${ }^{3}$

3 De hecho, creemos que en toda época y lugar cada movimiento y cada autor tienen que elegir entre tres posibilidades diferentes que bajo ningún concepto se pueden reducir a dos (cfr. BIANCHI 2016b: 25-27): la pureza y el esteticismo del arte por el arte, la profundidad reflexiva del intimismo, o la explícita mirada crítica hacia el mundo de las formas cercanas al realismo. La primera se encierra en la búsqueda de la perfección formal, la tercera es un testimonio de lo que el autor contempla desde la dimensión mimética, y la segunda proporciona un punto de vista personal, expresando el modo en que el escritor comprende o siente lo que acontece a su alrededor. 
Si la Poesía Social se propone como vehículo de un cambio efectivo — planteamiento que coincide con la definición del realismo socialista de György Lukács (1966: 24-25), casi al mismo tiempo, desde la segunda mitad de los cincuenta, se produce un cuestionamiento de esta tendencia, debido a la progresiva afirmación de un grupo de autores más jóvenes que promueven una poesía del conocimiento y observan lo que los rodea desde una perspectiva personal. Según Juan José Lanz, la responsabilidad de los autores del medio siglo para con la sociedad en la que se mueven (cfr. LANZ 2011: 52-66) tiene que ver con el concepto de poesía política, ${ }^{4}$ que surge y se afirma en esta época y se relaciona inicialmente con la poesía de la comunicación, y un poco más tarde con la del conocimiento ${ }^{5}$ de la Generación del 50 (cfr. Bianchi, 2018: 203-204). Esta última ya manifiesta la desilusión por haberse dado cuenta de que el régimen sigue intacto, pese a los cambios en la economía del país, y trata desde un punto de vista subjetivo e intimista las cuestiones sociales que generan el malestar compartido.

De igual manera, la inquietud interior de Núñez mana de su situación personal, pero se inserta en el desasosiego general de la España de la dictadura: su homosexualidad supone inevitablemente la negación de la misma, el aislamiento y la soledad. A pesar de la propaganda, el franquismo fracasa en el intento de generar consenso en torno al mito de la comunidad nacional y de una cultura propia, dejando que la Iglesia llene el vacío que de esto surge, mediante su labor adoctrinadora y promotora de la moral tradicional y religiosa (cf. Sevillano Calero, 1998: 87-89). Además de la represión estatal ejercida mediante el sistema judicial y penal del régimen, ${ }^{6}$ la represión ideológica se sirve del control y de la educación

En esta última modalidad se insertan los intimistas de la llamada Generación del 50, que se asientan en el debate estético de la poesía española de la posguerra.

4 Eugenio de Nora afirma que la estética de Espadaña fue «consecuencia consciente de una ética (y acaso, [...] de una política)» (1978: IX).

5 La polémica sobre los conceptos de poesía de la comunicación y del conocimiento tiene su origen en los aforismos de Vicente Aleixandre publicados en 1950 en las revistas Ínsula (1950a: 1-2) y Espadaña (1950b: 10171018), y luego recogidos en Obras completas (1968: 1570-1580 y 1581-1583): paradójicamente, el concepto de poesía como conocimiento se halla citado en los mismos aforismos aparecidos en el $\mathrm{n}$. 48 de la revista leonesa, en los que se reivindica la poesía como comunicación. De hecho, si la primera sentencia afirma que «La poesía no es cuestión de fealdad o hermosura, sino de mudez o comunicación» (1950b: 1017), la última aclara: «Fuente de amor, fuente de conocimiento; fuente de iluminación, fuente de descubrimiento; fuente de verdad, fuente de consuelo; [...]. Si alguna vez la poesía no es eso, no es nada» (1950b: 1018). Dos años más tarde, Carlos Bousoño publica la primera edición de Teoría de la expresión poética (1952), reafirmando la fórmula según la que la poesía es comunicación, refutada por algunos miembros de la Escuela de Barcelona: Carlos Barral (abril-junio 1953: 2326), Jaime Gil de Biedma (julio 1955: 96-101), Enrique Badosa (julio-agosto 1958: 32-46 y 135-159). Sobre la polémica han escrito, entre otros: Fanny Rubio (julio-agosto 1980: 192-216), José Luis García Martín (1986: 7387), Carme Riera (1988: 152-161), Dionisio Cañas (1996, v. 2: 33-43), Luis García Jambrina (2000: 50-63).

${ }_{6}$ En el art. 6, n. 20, de la Ley de Vagos y Maleantes de 1954 se lee: «A los homosexuales, proxenetas y rufianes, a los mendigos profesionales y a los que vivan de la mendicidad ajena, exploten menores de edad, enfermos mentales o lisiados, se les aplicarán, para que cumplan todas sucesivamente, las medidas siguientes: a) Internado en un establecimiento de trabajo o Colonia agrícola. Los homosexuales sometidos a esta medida de seguridad deberán ser internados en Instituciones especiales y, en todo caso, con absoluta separación de los demás. b) Prohibición de residir en determinado lugar o territorio y obligación de declarar su domicilio. c) Sumisión a la vigilancia de los delegados». La Ley de Peligrosidad y Rehabilitación Social de 1970 sustituye la referencia a los «homosexuales» con «los que realicen actos de homosexualidad», quienes «podrían ser declarados en estado 
del nacional catolicismo sobre los comportamientos inmorales; esto es aún más evidente en un pequeño pueblo conservador de la provincia de Córdoba. En este contexto, la disidencia de Núñez se plasma en su obra a través de la palabra y, más aún, del silencio. Recordemos al respecto que para Theodor Adorno (2003: 393-413) el compromiso no es una elección, sino una compleja relación con la realidad de la que toda la literatura procede, incluida la que quiere huir de ella para afirmar su autonomía. Solo en este sentido es posible hablar de compromiso en la escritura de Núñez.

\section{UNA POÉTICA PARA REIVINDICAR EL AMOR}

Núñez estructura su teoría poética sobre la relación entre vida, muerte, amor y poesía. Como ya se ha demostrado (Bianchi, 2009: 94-107), en su primer libro Elegía a un amigo mиerto (1954), el autor descubre que los primeros dos elementos no existen el uno sin el otro; en Los días terrestres (1957), entiende que no hay vida sin amor, aunque este supone sufrimiento y tristeza, ya que el tiempo aleja inevitablemente a la persona querida, como en Luis Cernuda. Después de la publicación de Los días terrestres, Núñez se esconde en un silencio que se interrumpe en 1980 con Poemas ancestrales (1980), donde explica que, si vida y poesía son inconciliables, solo la ausencia de la palabra escrita posibilita la verdadera existencia.

Hasta aquí, se ha marcado una separación entre la vida que es amor, y la poesía que coincide con la muerte; sin embargo, desde Ocaso en Poley (1982), las dos vertientes se unen y se confunden entre sí: el amor — que da sentido a la vida - se identifica con la escritura, es decir, con la muerte. Como consecuencia, en Cinco epístolas a los ipagrenses (1984), la destrucción total es la única conclusión posible; solo la última composición del libro presenta una variante al pesimismo, proponiendo una reconciliación con la existencia desde el carpe diem: la vida es efímera, pero persiste en el recuerdo y es la única certeza que tenemos (cfr. NúÑEZ, 2008: 180-181). La superación del contraste ocasiona las composiciones breves de Teselas para un mosaico (1985), donde la poesía se identifica con el amor; este guarda su primacía en Sonetos como pueblos (1989), donde lo terrenal está destinado a acabar, pero el verso es inmortal (cf. NúÑEz, 2008: 248) y ofrece al autor la oportunidad de vivir eternamente en sus obras. Núñez se reconcilia así con la escritura, tregua que se mantiene en Himnos a los árboles (1989b): las plantas, representación de los ipagrenses, constituyen el enlace con los orígenes y le permiten superar la separación entre realidad y poesía, entre vida y muerte, adelantando al presente la fusión con la naturaleza que en los primeros libros residía en el más allá. El autor logra vencer su mayor conflicto gracias a los árboles, aunque estar con ellos implica someterse a sus leyes, encerrarse en la soledad de su pueblo natal y renunciar - por lo menos aparentemente- a la libertad reivindicada por Cernuda en «Si el hombre pudiera decir lo que ama» (2005: 76-77); el vate inventa entonces el lenguaje del silencio para comunicar sin que lo entiendan.

peligroso y, por tanto, sometidos a «medidas de seguridad y rehabilitación» finalizadas a penalizar la reiteración y la habitualidad. 
Sin embargo, el optimismo desaparece en La gorriata (1990), donde la positiva visión panteísta deja paso al pesimismo cósmico, porque, si amor, vida, muerte y poesía coinciden, tal y como el verso es una imagen engañosa, cualquier esperanza en la existencia real es pura ilusión: nada es eterno. En 1994, Núñez compone el poema «Llueve» (2008: 302), donde concluye que todo acaba, incluso la poesía: la escritura, que representa la vida terrenal, comparte con ella el mismo destino de la muerte.

Mientras tanto, desde 1987, el aguilarense compone los aforismos filosóficos, los sofismas, que marcan la inseparable unión de oralidad y escritura en frases breves y sencillas que expresan las bases del complejo universo de su teoría literaria. El propósito declarado del nuevo género es contradecir cualquier expectativa del lector: el vocabulario inusual y la sintaxis alterada hacen que el significado pierda su validez para dar paso a una dimensión en la que el significante no puede alcanzar la designación y el silencio dice más que las palabras. Lo verdadero y lo falso se entremezclan, las mentiras se anulan mutuamente, el arte de la retórica pronuncia sus sentencias. En una poética construida sobre distintos niveles de engaño, el lector atento entenderá que la oscuridad oculta un mensaje encubierto acerca del amor y que, contrariamente a lo que el autor repite incansable, el verso canta la vida, sus sucesos y sus emociones, mintiendo u omitiendo detalles si es necesario, pero sin dejar de ser autobiográfico. La confesión más explícita se encuentra en la obra póstuma Rojo y sepia (2007), en cuyas páginas el poeta aclara que es diferente de las demás, porque no surge de la deformante perspectiva de la mentira, y en ella el «abrazo estéril» (2008: 338) ya no se esconde en la clandestinidad; se desvela así que la máscara del escritor que renuncia a la vida para escribir es un procedimiento retórico para defenderse de quienes no hubieran aceptado su homosexualidad. En otras palabras, en una reformulación del planteamiento cernudiano, la poética de Núñez se desarrolla sobre la posibilidad de transcribir secretamente el amor para que se vuelva imperecedero, para que los versos regalen la inmortalidad tanto al autor como a sus amantes, lo que queda patente en la composición «XVIII» de Rojo y sepia (2008: 322):

Os dejo testimonio

de que habéis existido.

Lo fuisteis todo para mí.

Vuestro perfume de oro

me acompaña en la muerte.

No vamos a morir.

\section{EL SILENCIO DE NÚÑEZ, LA POSTMODERNIDAD Y LA TEORÍA QUEER}

En los años de silencio, Núñez compone los poemas que marcarán su vuelta a la escritura en el panorama literario español de los años setenta, en el que las profundas transformaciones sociales del tardofranquismo, la gestación de la transición hacia la democracia, el impulso de la revuelta de 1968 y las nuevas referencias culturales de la música, del cine y del contexto urbano provocan la experimentación postmoderna de los Novísimos (CASTELLET, 1970). En esta época, la autonomía del arte y la posibilidad de expresar la realidad en el verso empiezan a cuestionarse desde el interior del poema, lo que marca el final de la supremacía de la estética realista. De hecho, desde Gérard Genette, la cultura contempo- 
ránea ha ido desarrollando una desconfianza en la palabra escrita (cfr. BLOCK DE BEHAR, 1984: 17), otorgando cada vez más valor significativo al silencio y rehabilitando expresiones como «yo miento», tan recurrentes en los textos de Núñez. De acuerdo con el principio de la cooperación interpretativa de Umberto Eco (1979: 17), esta mudez se dirige al conocimiento enciclopédico del lector, que posibilita el correcto posicionamiento del texto en su contexto y le permiten entender más allá del significado de las palabras. La naturaleza dialogante de lo no dicho se encomienda así a la interpretación del interlocutor y a su diálogo con la obra, lo que a su vez requiere que el silencio se presente como evidencia y parte relevante de la intención comunicativa del autor: la mudez se vuelve tema mencionado y objeto de elucubraciones metalingüísticas, como en la última etapa creativa de Núñez.

Miguel Casado ha comentado el silencio de nuestro autor en distintas ocasiones (2009; 2010; 2012), centrándose en los sofismas como alejamiento de la falsedad de la poesía, y en el abandono de la escritura entre 1960 y 1980. Pese a ello, sería conveniente profundizar más bien en la retórica del silencio, tanto en los aforismos como en los versos del aguilarense. Para aclarar a qué nos referimos cuando nombramos el silencio de Núñez, veamos la definición de «escritura al margen» de Antonio Crespo Massieu (2007: 67):

Escritura al margen, [...], dejando siempre abierta una nueva pregunta, una nueva palabra, inconclusa, esperando ser recibida; dejando siempre un hueco, un margen (un margen al margen del margen), un espacio en blanco para que lo habite otra palabra o el silencio; sin frontera, sin línea de separación. Los intersticios del poema, el verso, su respiración, sus pausas son ya margen, una escritura nunca cerrada, que se abre en la lectura, que se reinicia (como pregunta e indagación, como repetición incluso) en cada nuevo proceso de escritura.

El margen es la voz del silencio que sugiere detrás de las palabras, a la que se alude en la conclusión de la monografía Vicente Núñez: parole come armi (BIANCHI, 2011: 233) donde se cita el «género de sospecha auspiciada» y «de la rendija» ${ }^{7}$ (NúÑEZ, 2010: 96): en su escritura, los espacios vacíos comunican, el signo lingüístico es necesariamente oscuro, y las pausas entre una palabra y otra invitan a la suposición y al presagio. En Núñez encontramos todas las vertientes que Ramón Peralta menciona en su «El silencio en la poesía» (2005, s.p.): el fragmentarismo, las omisiones, las vacuidades, los espacios blancos, lo no dicho, las referencias explícitas e implícitas a la ausencia y a la mentira, el silencio reivindicado como presencia y plenitud —recordando en esto a Antonio Gamoneda (1977)—, el alejamiento voluntario de la creación durante más de veinte años, el abandono de la escritura en verso durante la última etapa de su trayectoria literaria. Por esta razón, como se ha planteado otras veces (Bianchi, 2009; 2012; 2013, 2016a), el silencio se impone como paradigma para cualquier exégesis de la obra de Núñez.

Por su poética basada en el engaño y en las omisiones deliberadas, expresión de una crisis interior, por el acercamiento al género aforístico y, sobre todo, por la voluntad de romper con el lenguaje literario tradicional, cabría relacionar la segunda época de la trayectoria de Núñez - a partir de la vuelta a la escritura en los ochenta- con los productos artísticos vin-

7 Reza el texto completo del sofisma: «Replicas a lo serio falso. Porque detrás de esta seriedad, hay un ojo acechando. Éste con el que no habíamos contado; género de la sospecha auspiciada. El género de la rendija» (NÚÑEZ, 2010: 96). 
culados a los modelos epistemológicos de la Postmodernidad ${ }^{8}$ y a su tendencia a la deconstrucción del sujeto, a las identidades marginales, a la fragmentación del objeto artístico, a las nuevas posibilidades combinatorias, al pastiche y a formas innovadoras tanto de la creación como de la lectura (cfr. García Gabaldón y VALCÁrcel, 1998: 441-442). En la Postmodernidad, con frecuencia la transgresión, la ironía, la ruptura, la antinomia y en general muchos de los recursos retóricos que Núñez emplea no se limitan al juego formal, sino que tienen la finalidad de involucrar al lector en una profunda exploración sobre el ser, la identidad y la condición del hombre, lo que ocurre en nuestro autor, heredero de la teoría poética de Cernuda, renovada y reinventada en sus creaciones. Además, debido al papel determinante de la comunicación en la sociedad postmoderna (cfr. HurTado León y Toro GarRido, 2007: 46), a menudo las expresiones literarias neovanguardistas apuestan por la desestructuración lingüística, destruyendo la sintaxis, rompiendo con las reglas gramaticales, inventando neologismos inesperados y buscando, en ocasiones, una vuelta a la oralidad «caracterizada por la utopía de escribir con la voz, hablar con lo escrito, a través de modos lingüísticos híbridos» (GARCíA GABALDón y VALCÁRCEL, 1998: 443). Al mismo tiempo, sobre todo en el género ensayístico, se proponen preguntas metafísicas o reflexiones acerca de cuestiones metaliterarias que no pretenden encontrar respuestas (GARCía GABALDón y Valcárcel, 1998: 448-449). Como hemos visto, esto ocurre tanto en los versos como en los sofismas de Núñez, quien forja una nueva filosofía postmoderna basada en la comunicación.

Sin embargo, hay otra característica que afiliaría a Núñez a la Postmodernidad, aunque siempre teniendo presente que se trata de una personalidad en los márgenes del canon, que tan solo recupera de las corrientes de pensamiento y de las modas literarias los elementos que sean funcionales a su original manera de ver, interpretar y expresar el mundo en su producción. Nos referimos a la teoría queer, con sus planteamientos sobre la conformación de una identidad que supere la construcción cultural genérica impuesta, y con su antinormatividad como rebelión o protesta en contra de la norma y de los valores consagrados. Entre los eminentes estudiosos del tema, Judith Butler ha abierto importantes líneas teóricas en Género en disputa (2001), centrándose luego en los límites discursivos relacionados con la movilidad y la inestabilidad de una subjetividad sexual transferible y preformativa, en Cuerpos que importan (2002), cuyo título sugiere la centralidad de la corporalidad en la reflexión.

Si los discursos ordenan la realidad y hasta la crean, desde la palabra y el verso se puede conformar una visión del yo y de su deseo de que sea mutable y alternativa a las hegemónicas o ritualizadas, puesto que, de acuerdo con Butler (2002: 18):

8 Tras el final del idealismo moderno, la sociedad postmoderna compleja y caótica ha generado nuevos modelos epistemológicos —o modos de conocer la realidad y de entender el mundo- que todavía no han terminado de configurarse; entre los que se asentaron en la segunda mitad del siglo XX, cabe mencionar: el deconstruccionismo de Jacques Derrida; el postestructuralismo de Jacques Lacan, Roland Barthes y Claude LéviStrauss; el constructivismo de Gaston Bachelard, Niklas Luhmann, Edgar Morin y Jean Piaget, entre otros. Lo que ya se ha aclarado es que el Postmodernismo propende por una racionalidad dialógica y un saber subjetivo y cualitativo, es decir, sus modelos epistemológicos se basan en los paradigmas principales de la intercomunicación y la intersubjectividad, a los que se suman la flexibilidad, la particularidad, la verdad cualitativa y la condición holística (cfr. Hurtado León y TORO GARrido, 2007: 46-49). 
En realidad, son las inestabilidades, las posibilidades de rematerialización abiertas por este proceso las que marcan un espacio en el cual la fuerza de la ley reguladora puede volverse contra sí misma y producir rearticulaciones que pongan en tela de juicio la fuerza hegemónica de esas mismas leyes reguladoras.

Ya hemos visto que la teoría poética de Núñez se construye alrededor de la desestabilización de las expectativas del lector precavido, para animarlo a que comprenda las razones y busque los significados ocultos detrás de las palabras: elige el silencio y la mentira como procedimientos retóricos para reafirmar la libertad de un amor que quiere superar las restricciones tradicionales. Se trata entonces de un habla subversiva, concepto que encuentra su teorización en otro libro de Butler, Lenguaje, poder e identidad (2004: 261):

La palabra que hiere se convierte en un instrumento de resistencia, en un despliegue que destruye el territorio anterior de sus operaciones. Este despliegue significa enunciar palabras sin una autorización previa y poner en riesgo la seguridad de la vida lingüística, el sentido del lugar que ocupa uno en el lenguaje, la palabra de uno justamente como uno la dice. [...] El habla subversiva es la respuesta necesaria al lenguaje injurioso, un peligro que se corre como respuesta al hecho de estar en peligro, una repetición en el lenguaje que es capaz de producir cambios.

Si el planteamiento de la trayectoria poética de Núñez descrita en el tercer párrafo procede paralelamente a la construcción de su habla subversiva, la máxima expresión del silencio sonoro, rebelde y queer se halla en los sofismas. Entre los aforismos, hay ejemplos incuestionables que además juegan con la ironía (NúÑEZ, 2010):

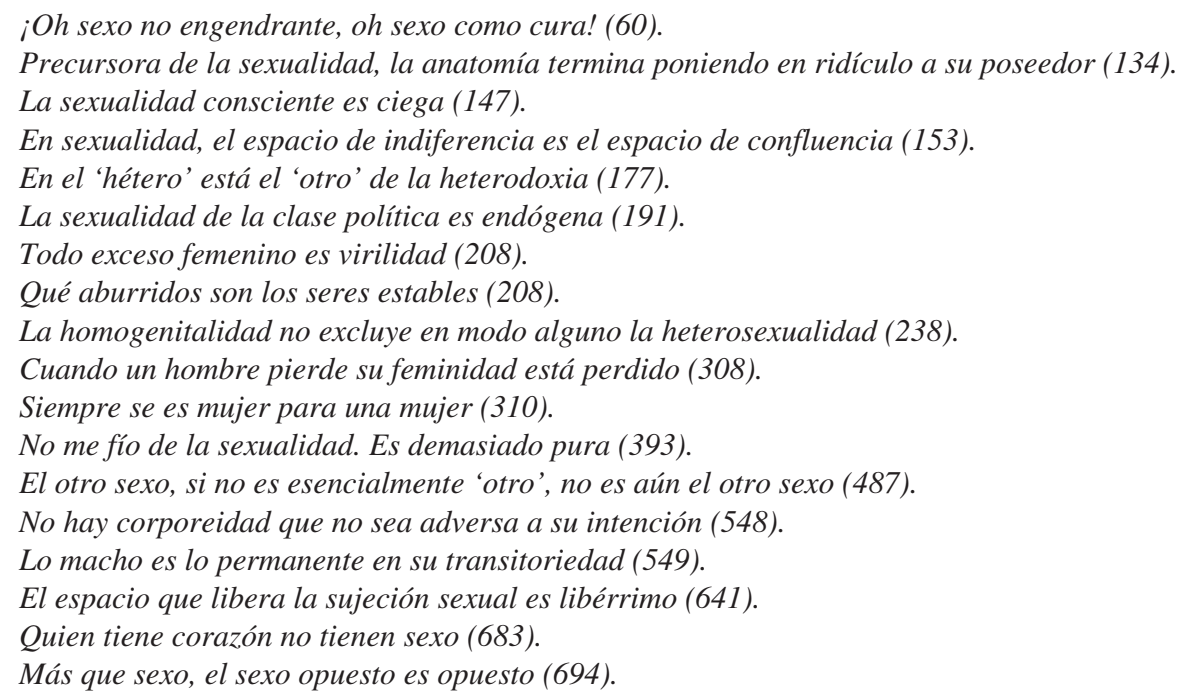

\section{EL DESCUBRIMIENTO DEL EROS Y DE SU LADO OSCURO}

Antes de culminar en los sofismas, el código del silencio como recurso retórico se va forjando en las distintas etapas creativas y vitales de Núñez: tras descubrir el amor en la primera y su lado oscuro en la segunda, en la que el poeta entiende la necesidad de ocul- 
tar parte de la verdad, en la tercera da forma al juego de la mentira que desvela, del ocultamiento que deja entrever, de las palabras como armas (cfr. BIANCHI, 2011) y rebelión.

El origen coincide con la temporada en la que Núñez reside en Málaga, entre 1953 y 1959; volverá a Aguilar tras una breve temporada en Madrid, donde no se siente a gusto por el alboroto y el frenesí de la vida de la capital. En la ciudad más abierta de Andalucía -incluso en la época franquista-, sin los condicionamientos psicológicos del pequeño pueblo tradicionalista de la provincia de Córdoba, el poeta firma versos donde la sensualidad se confunde con las metáforas naturales, como en los poetas de Cántico. En la añoranza del compañero perdido de Elegía a un amigo muerto, por ejemplo, se lee (2008: 33):

Saltimbanqui de las estrechas gotas que esperan las libélulas, sobre sus lomos fresa llegas a los jardines míos, a mis pasos de ahora, en estos pies buscándote a sirga de tu impulso, húmedos de tu tacto por mis dedos sentido.

El mismo procedimiento se mantiene en Los días terrestres, donde el recuerdo de las primeras relaciones fugaces sigue fundiéndose con los símbolos vegetales. Acerca de la llegada de la estación que trae consigo el renacer del amor, en «La parroquia», Núñez escribe (2008: 41): «y el chorro de la fuente era como un hermoso / lirio verde de vidrio turbador que gemía». O, en «Después de la vendimia» (2008: 49):

Yo te ofrecí granadas de encendida corteza
y membrillos que tienen una dulce pelusa,
y por la carretera te ofrecí los cristales
transparentes y hermosos que dan los cubariles.

En el poemario, los primeros acercamientos se rememoran con claras referencias a lo corporal, aunque supeditadas a la inocencia de la edad temprana, como en «Vacaciones» (2008: 44):

¿Qué podía en su abrazo de eternidad la infancia
contra el tiempo, tan pronto detenido de veras,
si aquellos zagalillos eran sólo tu mano
extendiéndose rauda como un temblor alado
y la estrella dorada de tus ojos debía
perderse en el espacio de mi alma reciente?

La «carne viva aguardándote / desmemoriada, llena de indecible deseo» (2008: 66), como Núñez la define en «Hora de llanto», se alterna a los abandonos y a la soledad, al «olor de las lágrimas» (2008: 65) de «El último encuentro», en un libro que se cierra con el sufrimiento por haber vivido, de claro legado cernudiano: «Traigo el amor podrido de pureza y no puedo / librarme de su oscuro e invencible venablo» (2008: 72), como reza «El viejo sollozo». De las primeras relaciones que todavía conllevan cierta ingenuidad, el sujeto poético aprende la sensualidad, pero también la congoja que esta provoca. Pese a ello, como en el maestro de la Generación del 27, en Núñez el dolor merece la pena; lo corro- 
bora el final de «La despedida», que además anuncia el silencio que sigue a la publicación de Los días terrestres: «es sólo porque debo perderme totalmente / y arrojar la amargura tan dentro de mí mismo / que por ella, algún día, sepa al fin que he vivido» (2008: 76).

Entre 1958 y 1979, Núñez se aleja del panorama literario y evita dar sus textos a la imprenta, lo que no implica que no escriba. En 1958, la muerte de la madre le supone una profunda crisis personal y, en 1959, vuelve a Aguilar de la Frontera para exiliarse allí hasta el final de su vida: en su pueblo, espera recobrar el contacto con los orígenes que se había desvanecido por la pérdida de quien lo había llevado en su vientre.

Tras los años del silencio, sale Poemas ancestrales, en el que el amor conlleva algo negativo que va más allá del simple abandono: en «Resurrección de la esperanza», la «vibración perfecta y misteriosa» depende de «los tercos designios del destino, / cuyas dádivas cobra de manos de la muerte» (2008: 88). El escenario cordobés tampoco es alentador, puesto que se describe como una tierra de «vino, / sensualidad aparente y hermosura», a la vez que de «antigua y seca indiferencia» (2008: 89), como se lee en «Isla»; además, quien allí reside «puede dejarse confundir oculto / tras la sospecha hostil de la asamblea» (2008: 112), según se dice en «La ciudad». En esta segunda etapa, el Eros se carga entonces de matices oscuros y de desconfianza. De hecho, desde Ocaso en Poley, el sentimiento a menudo se asocia con la esterilidad y con la culpa, o mejor dicho, con la felix culpa de quien sabe que su sensualidad es incompatible con la moral común, pero considera que lo positivo prima sobre lo negativo. Tenemos un ejemplo en «Consejo», donde la persona deseada y nunca conquistada por el sujeto poético aparece con nombre propio (2008: 127):

Advirtiéndome Pablo - y su voz tras de la afable
tiniebla telefónica- que no fuera insensato
y de mí te arrojara definitivamente,
acaté yo sumiso esa intención benévola
como si desde el fondo fatal de las edades
decretado estuviese. Mas sentí en el vacío
victorioso y culpable que entonces sobrevino,
que un cuchillo me hendía del pavor de la muerte.
Y fui total, y supe, oh gratísimo Pablo,
lo que en verdad era amarte y no haberte perdido.

La insensatez, la culpabilidad acompañada por la sensación del triunfo y la muerte como metáfora del final del amor forman parte de la herencia del que Biruté Ciplijauskaité (1991: 29-40) reconoce como «el lenguaje del deseo» homosexual de algunos de los poetas de la Generación del 27: en su artículo, la hispanista propone la teoría según la que Luis Cernuda, Federico García Lorca, Vicente Aleixandre y Emilio Prados aprovechan el acercamiento a las vanguardias para crear un código compartido que exprese «lo que más les atormenta sin pronunciarse claramente» (1991: 34), en el que el impulso sexual es sublimado y doloroso a la vez. Este código deja su huella en la lírica del medio siglo, sobre todo en el intimismo de los de Cántico —entre los que tantas veces se ha incluido a Núñez (VIllena, 2007: 281327; CARnero, 2009: 125-137 y 385-418; IngladA, 2010: 201-217), pese al ya señalado desacuerdo de algunos (BIANCHI, 2011: 60-74) - y de la denominada Generación del 50. 
En línea con su teoría poética - y con la mentira según la cual el amor pertenece a la vida, mientras que la escritura coincide con la muerte, metáfora de la soledad-, el aguilarense añade en «Yo te amé en silencio», de Ocaso en Poley (2008: 152):

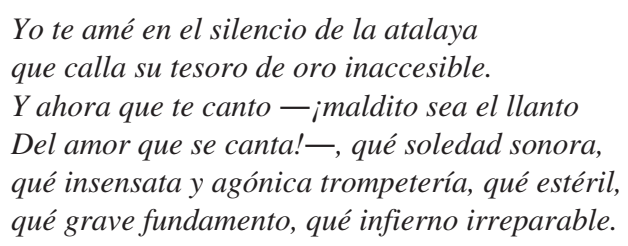

Según Ciplijauskaité (1991: 38), ya en el «lenguaje del deseo» de la Generación del 27 , cuando se habla de amor estamos en el plano del deseo, en el que la presencia no es real y el sentimiento se asocia con la destrucción, como en el título de la conocida obra de Vicente Aleixandre (1945). Lo mismo se aprecia en el poema de Núñez, que incluye además una cita encubierta de «la música callada, / la soledad sonora» del Cántico espiritual de San Juan de la Cruz (2002: 20), y que hace referencia explícita a la esterilidad. La imposibilidad de la reproducción vuelve en las Epístolas a los ipagrenses, el primero de los dos libros dirigidos a los habitantes de Aguilar, donde ya se insinúa el barroquismo finalizado a la deliberada dificultad de comprensión, que culminará en los Himnos a los árboles. El íncipit de la «Epístola I» reza (2008: 171):

Como el campo de extenso, pero, ay, como él, tan infecundo, subsiste el corazón.

Oh infausto fruto, oh rota

caña que te coronas

en el desvalimiento

y cedes al envite

del efímero aire,

¿quién es aquel que a izarte y a segarte

se atrevería, dime,

si no es el tronco mismo

de la aridez perpetua y su impostura?

Al final del fragmento aparece la impostura, actitud que se mantiene y se intensifica a lo largo de la última etapa de la trayectoria creativa de Núñez.

\section{LA RAZÓN DEL HABLA SUBVERSIVA: EL PACTO DEL SILENCIO}

Las falsas apariencias se vuelven entonces el fundamento del verso, como confirma la composición «XXVI» de Teselas para un mosaico (2008: 212):

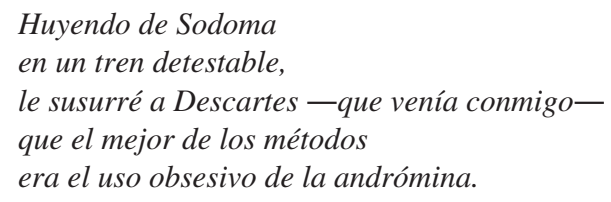


El embuste y el enredo como modo de obrar, el pensamiento silogístico procedente de la filosofía como cimiento sobre el que se construye la teoría poética, y la inevitable presencia del olvido deliberado u ocultamiento. Núñez lo explicita también en uno de sus sofismas — «Ensortijar el lenguaje para que el enemigo no te coja desprovisto de la última trampa que te deja: el enredo» (2010: 317) — y, aunque de forma más velada, en la tercera composición de «En los tiempos antiguos» (2008: 228):

Cuando escribas, olvídate

de ti. Tan inasible

como tu hermosura

es la orquídea del mundo.

Olvido es mi fragancia.

Lo bello de la realidad personal —el sentimiento- quedará escondido detrás de las metáforas complejas y del lenguaje rebuscado de Núñez, porque así lo impone el hecho de vivir en un lugar que lo encarcela, lo esclaviza y lo acongoja, lo que proclama en «Frontera», de Sonetos como pueblos (2008: 247):

Lo quise y puse todo en tu frontera, trazo de hiel que hallé al azar un día.

Reino de mi abrojal, ¿quién no se hacía propicia presa de tu airada hoguera? Cuervos que encaramándose a la fiera de impuro seno amamantaron cría.

¡Como si el corazón no fuera el guía de la ceguera! Oh trampas de ramera, menos sumisa cuanto más lasciva. Vine a tu inmundo harapo y fui cogido. Quise arrostrar la soga y la cadena tras la muralla de tu entraña esquiva. Quise y no supe. Pero te he querido.

Canta en mi sangre un llanto de azucena.

Una atenta lectura de los Himnos a los árboles desvela la razón de la falta de libertad: las plantas, interlocutores simbólicos de un monólogo que recuerda las Cinco epístolas a los ipagrenses, son de nuevo los habitantes de Aguilar, los majestuosos depositarios del ser que deberían acoger al sujeto poético, reconocerlo como su hermano y que, sin embargo, se demuestran incapaces de aceptarlo. Lo corrobora el «Himno IV» (2008: 264):

Yo era vuestro ansiado,

el que debía consumarse en el rango

de las ocultas evidencias,

quien vestiría la túnica

de la desnudez y el desposorio.

[...]

$Y$ me repudiáis en las praderas

con la agreste zampoña

de los atribulados dioses. 
En el «Himno V», la voz poética que sigue hablando en primera persona confirma su voluntad de acercarse a los árboles, pero sabe que esto implica sufrimiento y desilusión (2008: 265-266):

Y os descubría, oh espléndidos,

vestidos de mi abolengo;

con ademán y charla que he entendido,

$y$ con costumbres arrebatadas

de antigüedad.

[...]

Todos mis descarríos

¿qué fueron sino ignorancia

de vosotros, siempre enredándome

en el lentisco y en la aulaga de la zozobra;

siempre ante un mismo solecillo

escuálido, con la bufanda

y los ungüentos de la enfermedad?

[...]

¿Debo disponerme a cantaros

con instrumentos de alegría?

A estrujar mi ser he venido,

a esparcirlo y a dároslo.

El sujeto lírico elige entregarse a las plantas, pese a su visión vetusta desde la que es considerado enfermo, errátil e inoportuno. Es muy probable que el poema esté relacionado con lo que relata Luis Antonio de Villena acerca de los primeros años de Núñez tras la vuelta a Aguilar (2009: 37):

[...] en los primeros años sesenta el bibliotecario del pueblo, atildado y quizás afeminado - para los parámetros rudísimos de aquel tiempo- recibía sin inmutarse las burlas y los dicterios de parte de la muchachada del lugar que tanto quiso, y aun de niños más pequeños que alguna vez (en aquellos juegos crueles, tan de aquella infancia bruta) hasta le tiraron piedras...

Un trato parecido al relatado en el fragmento, igualmente desagradable e injusto, se vuelve más parecido a una tortura en la denuncia explícita del «Himno VII» (2008: 269270), que pasa de la primera persona singular a la plural:

Semejantes a esclavos,

nos despojaron de nuestros atributos,

y nos hicieron rendir peso

ante tribunos y fielatos.

Hasta la horca miserables,

fuimos tasados como viruta y oro bajo,

sirgados sobre los turbulentos ríos de la negociación

hacia dársenas y lupanares;

sacrificados como reses

y exorcizados conforme a la doctrina

de quienes ofician en el negocio del latrocinio.

Extrajeron nuestro perfume

y seccionaron nuestros músculos 


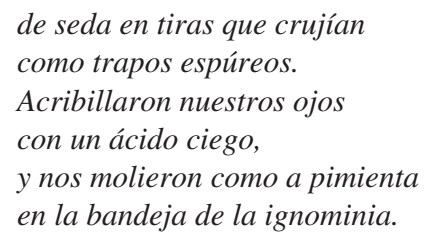

Frente a esta inaceptable actitud, Núñez ofrece la solución de un «silencio hablante» (2010: 559) que sugiere sin nombrar, que juega a confundir el difícil amor hacia una persona con el sentimiento hacia la poesía — «QQué porcentaje de mi mensaje tienen entendido?» (2010: 254)—, que anula las identidades tradicionales para asentar una nueva perspectiva: «Ser hombre o ser mujer constituye, sin duda una conquista personal. Ser hembra o ser macho, un episodio genético demasiado impuesto» (2010: 43).

\section{CONCLUSIONES PARCIALES}

Es sabido que la biografía de un poeta no tiene por qué reflejarse de forma fiel en sus versos; sin embargo, es igualmente incuestionable que la realidad vivida es la plataforma de arranque de cualquier expresión verbal y artística del ser humano, sobre todo en lo que se refiere a sus turbamientos más íntimos: «Yo soy yo y mi circunstancia», como afirma José Ortega y Gasset (1914: 43). O, en palabras del recién fallecido Pablo García Baena en una entrevista todavía inédita acerca de su amigo Vicente Núñez: «La poesía es un diario [..], refleja cosas reales. Es casi un acto de notario. [..] La realidad es todo; la poesía es el amor hacia todo lo que es la vida». ${ }^{9}$ Si para Sigmund Freud (1988, vol. VI: 1347) el verso es el lugar donde toman forma los sueños y los deseos irrealizables, en las obras de Núñez encontramos historias de amor vividas plena y libremente, y la creación subversiva de una subjetividad no tradicional, que le permite reconocerse y darse a conocer, más allá de las limitaciones impuestas.

Con esta finalidad, aunque todavía latente al principio, Núñez se inserta en el panorama poético del medio siglo: se acerca al estilo de los amigos de Cántico que reivindican la sensualidad homosexual en sus primeros libros Epístola a un amigo muerto y Los días terrestres, cuya publicación en 1954 y en 1957 respectivamente le otorgan el derecho a pertenecer al grupo andaluz de la Generación del 50. Con esta comparte también el tono íntimo no exento de un malestar de fondo del yo que depende de la situación que lo rodea, y la ironía que lentamente conquista espacio desde la tercera colección, Poemas ancestrales, escrita en los años del silencio aunque ve la luz en 1980. Al volver a la literatura tras la larga ausencia, sus versos se cargan cada vez más de dualidades, de rupturas, de preguntas sin respuestas, de intentos fallidos de búsquedas de identidad, de recursos que quieren sorprender al lector, de reflexiones metalingüísticas sobre la imposibilidad comunicativa de la palabra. Al mismo tiempo, la burla se vuelve escarnio o cinismo, la tradición y la modernidad se confunden, la métrica clásica se alterna a acentuaciones inesperadas, los poemas cortos de

\footnotetext{
9 De una entrevista inédita con Pablo García Baena, en su casa de Córdoba, del 10 de mayo de 2007.
} 
Ocaso en poley de 1982, Teselas para un mosaico de 1985 y Rojo y sepia de 2007 se turnan con el monólogo interior de las Epístolas a los ipagrenses de 1984 y de los Himnos a los árboles de 1989, o con los sonetos de Sonetos como pueblos de 1989 y del desesperanzado poemario La gorriata de 1990.

Finalmente, llegamos a los sofismas, es decir, al triunfo de las elucubraciones pseudofilosóficas, a la aparente preeminencia de la oralidad en la escritura, a la alteración de las normas gramaticales, al protagonismo del engaño deliberado, a la primacía de las contradicciones y de las desviaciones del significado. A todo esto se suman una cantidad impresionante de referencias cultas procedentes de la literatura, la filosofía, la lingüística de toda época y lugar, y, sobre todo, la presencia constante del legado de la Realidad y el deseo (2005) cernudianos: si el maestro reivindica la libertad de hablar de su amor anticonvencional y encuentra un código que le permita reclamar su derecho, el discípulo forja su habla subversiva basada en el silencio como forma de resistencia y rebelión que anule cualquier dogma impuesto o idea preconcebida, para que su visión y experiencia del amor lleguen plenamente a quienes no se queden en el nivel superficial de la mentira y de la apariencia.

Sin duda, Núñez se asienta en el debate postmoderno acerca de lo queer, cuyo primer propósito es quebrar las convenciones para proponer un nuevo paradigma interpretativo de la realidad y del sujeto mismo. Tras construir su perspectiva innovadora, el vate obliga al lector a que observe desde su mismo punto de vista; el yo deja así de ocultarse y se revela al alcanzar el objetivo último de su quehacer poético: «Nuestros actos devienen y, por tanto, ya han perdido su verdadera intencionalidad: ocultarse» (2010: 181).

\section{REFERENCIAS BIBLIOGRÁFICAS}

AA. VV. (1978): Espadaña. Revista de poesía y crítica, ed. facsimilar de los nn. 1-48 (1944-1950), León, Espadaña Editorial.

Adorno, TheOdor (2003): Obra completa, Madrid, Akal.

AleiXANDRe, Vicente (I945): La destrucción o el amor [1935], Madrid, Alhambra.

- (noviembre 1950a): «Poesía, moral, público», Ínsula, 59, pp. 1-2.

- (diciembre 1950b): «Poesía: comunicación», Espadaña, 48, pp. 1-2 [también en: AA. VV. (1978): Espadaña. Revista de poesía y crítica, ed. facsimilar, León, Espadaña Editorial, pp. 1017-1018].

- (1968): Obras completas, Madrid, Aguilar.

Althausser Louis (1970): Ideología y aparatos ideológicos del Estado. Freud y Lacan, Buenos Aires, Nueva Visión.

Austin, John L. (1962): How to do Things with Words, Oxford, Oxford University Press.

Badosa, Enrique (Julio-agosto i958): «Primero hablemos de Júpiter. La poesía como medio de conocimiento», Papeles de Son Armadans, Xxvir y xxix, pp. 32-46 y 135-159.

Bajtín, Misaíl (2003): Problemas de la poética de Dostoievski [1929], México D. F., Fondo de Cultura Económica.

Barral, Carlos (abril-JUnio I953): «Poesía no es comunicación», Laye, 23, pp. 23-26.

Barthes, Roland (2003): Ensayos críticos [1964], trad. de Carlos Pujol, Buenos Aires, Seix Barral.

BianChi, Marina (PRimaVera-VERANo 2009): «Vicente Núñez: el disfraz es secuaz de la verdad», $E l$ Maquinista de la Generación, 17, pp. 94-107.

- (2011): Vicente Núñez. Parole come armi, Barcellona Pozzo di Gotto, Edizioni Smasher. 
- (2012): «La 'potencia no designativa' del lenguaje, en los aforismos metalingüísticos de Vicente Núñez», en AA. VV., Metalinguaggi e metatesti. Lingua, letteratura e traduzione, Actas del XXIV Congreso Aispi Università degli Studi di Padova, 23, 24, 25 y 26 de mayo de 2007, Roma, A.I.SP.I. - Instituto Cervantes, pp. 115-126.

- (2013): «El silencio de la palabra en Vicente Núñez», en Leonor María Martínez Serrano (ed.), Vicente Núñez, poeta y filósofo universal, Montilla, Fundación Vicente Núñez — Junta de Andalucía - Centro del Profesorado Priego-Montilla, pp. 35-56.

- (2016a): «Vicente Núñez: una disidencia atípica», en María Payeras Grau (ed.), Fuera de foco. Aproximaciones a la diversidad poética del medio siglo, Madrid, Visor, pp. 47-65.

- (2016b): De la Modernidad a la Postmodernidad. Vanguardia y Neovanguardia en España, Sevilla, Renacimiento.

- (2018): «Poesía y comunicación política en la España de los cincuenta», en Maria Vittoria Calvi, Beatriz Hernán-Gómez Prieto, Giovanna Mapelli (eds.), La comunicazione specialistica. Aspetti linguistici, culturali e sociali, Milano, Franco Angeli, col. Lingua, traduzione, didattica, pp. 202215.

BLOCK DE BeHAR, LISA (I984): Una retórica del silencio. Funciones del lector y los procedimientos de la lectura literaria, México D. F., Siglo XxI.

Bousoño, CARLos (1952): Teoría de la expresión poética, Madrid, Gredos.

Butler, Judith (200I): El género en dísputa. El feminismo y la subversión de la identidad [1990], Buenos Aires, Paidós.

- (2002): Cuerpos que importan: sobre los límites materiales y discursivos del 'sexo' [1993], Buenos Aires, Paidós.

- (2004): Lenguaje, poder e identidd [1997], trad. y prólogo de Javier Sáez y Beatriz Preciado, Madrid Síntesis.

CAÑas, Dionisio (i 996 ): «La poesía como complicidad. Las polémicas poéticas de los años 50», en AA. VV., Jaime Gil de Biedma y su generación. Actas del Congreso, Zaragoza, Diputación Provincial, v. 2, pp. 33-43.

Carnero, Guillermo ( 1976): El grupo Cántico de Córdoba, Madrid, Editora Nacional.

- (2009): El grupo Cántico de Córdoba. Un episodio clave de la historia de la poesía española de posguerra, Madrid, Visor.

Casado, Miguel (2004): El vehemente, el ermitaño, Benalmádena, Ediciones de Aquí.

- (2009): «Las palabras como acción (notas sobre los sofismas)», en Celia Fernández Prieto (ed.), Vicente Núñez. Oralista, poeta, sofista, Sevilla, Renacimiento, pp. 46-72.

- (2010): «Una lectura de los sofismas de Vicente Núñez», en Vicente Núñez, Poesía y sofismas. II. Sofismas, ed. Miguel Casado, Madrid, Visor, pp. 7-27.

- (2012): «Los sofismas de Vicente Núñez», en Leonor María Martínez Serrano (ed.), Vicente Núñez. Patrimonio vivo de Aguilar de la Frontera, Montilla, Fundación Vicente Núñez — Junta de Andalucía - Centro del Profesorado Priego-Montilla, pp. 29-57.

Castellet, José María (ED.) (1970): Nueve novísimos poetas españoles, Barcelona, Barral.

Cernuda, Luis (2005): La realidad y el deseo (1924-1962), Madrid, Alianza.

Ciplijauskaité, Biruté (I99i): «Transgresión, ruptura y el lenguaje del deseo en los poetas de la Generación del 27», en Carla Prestigiacomo y Maria Caterina Ruta (eds.), Dai modernismo alle Avanguardie, actas del congreso AISPI, Palermo, mayo de 1990, Roma, AISPI, pp. 29-40.

Crespo Massieu, Antonio (abril 2007): «La poesía y los márgenes», Viento Sur, 91, pp. 67-76.

Cruz, SAN JuAn De la (2002): Cántico espiritual y poesía completa, ed. Paola Elia y María Jesús Mancho, estudio preliminar de Domingo Ynduráin, Barcelona, Crítica.

Eco, Umberto (i962): Opera aperta, Milano, Bompiani.

- (1979): Lector in fabula, Milano, Bompiani.

Even-Zohar, Itamar ( I979): «Polysystem Theory», Poetics Today, I, 1-2, pp. 287-310. 
Freud, Sigmund (I988): «El poeta y los sueños diurnos» [1908], en Id., Obras completas, Barcelona, Orbis, vol. VI, pp. 1343-1348.

Gamoneda, Antonio (1977): Descripción de la mentira, León, Institución Fray Bernardino de Sahún - CSIC - Diputación Provincial.

García Gabaldón, Jesús y ValcárCel, Carmen (i998): «La neovanguardia literaria española y sus relaciones artísticas», en Javier Pérez Bazo (ed.), La vanguardia en España, Toulouse — París, C. R. I. C. \& Ophrys, pp. 439-482.

García Jambrina, Luis (2000): La promoción poética de los 50, Madrid, Espasa-Calpe.

García Martín, José Luis (I986): La segunda generación poética de posguerra, Badajoz, Diputación Provincial.

Gil de Biedma, Jaime (Julio I955): «Poesía y comunicación», Cuadernos Hispanoamericanos, 67, pp. 96-101.

Greimas, Algirdas Julián y Courtés, Joseph (I979): Sémiotique. Dictionnaire raisonné de la théorie du langage, Paris, Hachette.

Hurtado León, Iván y Toro Garrido, Josefina (2007): Paradigmas y métodos de investigación en tiempos de cambio, Caracas, Los libros de El Nacional.

Inglada, Rafael (ED.) (2010): Cántico 2010 [catálogo], Córdoba, Sociedad Estatal de Conmemoraciones Culturales - Junta de Andalucía - Fundación Provincial de Artes Plásticas Rafael Botí.

Iser, Wolfgang (1974): The Implied Reader: Patterns of Communication in Prose Fiction from Bunyan to Beckett, Baltimore and London, The Johns Hopkins University Press.

Jauss, Hans Robert (I 982): Toward an Aesthetic of Reception, trad. de Timothy Bahti, Minneapolis, University of Minnesota Press.

Kristeva, Julia (I98 I): Semiótica 2 [1969], trad. de José Martín Arancibia, Madrid, Fundamentos.

LANZ, JuAn José (abril 2011): «El compromiso poético en España hacia mediado del siglo xx», Revista www.izquierdas.cl, 9, pp. 47-66, http://www.izquierdas.cl/images/pdf/2011/07/Juan-Jose-Lanz1. pdf, acceso 31-10-2020.

Lotman, Juriu (1978): La estructura del texto artístico [1970], Madrid, Istmo.

LuKács, György (I966): Problemas del realismo [1955], México D. F., Fondo de Cultura Económica. Morris, Charles (1946): Signs, Language and Behaviour, New York, Prentice Hall.

Nora, Eugenio de (I978): «ESPADAÑa, 30 AÑOS DESPUÉS», EN AA. VV., ESPADAÑa. Revista de poesía y crítica, ed. facsimilar, León, Espadaña Editorial, pp. IX-XVII.

NÚÑEZ, VICENTE (I954): Elegía a un amigo muerto, pórtico de Vicente Aleixandre, prólogo de Alfonso Canales, Málaga, Imprenta Dardo, col. A Quien Conmigo Va.

- (1957): Los días terrestres, Madrid, Rialp S.A., col. Adonais.

- (1980): Poemas ancestrales, prólogo de Pablo García Baena, Sevilla, Calle del Aire.

- (1982): Ocaso en Poley, Sevilla, Renacimiento.

- (1984): Cinco epístolas a los ipagrenses, Córdoba, Diputación Provincial.

- (1985): Teselas para un mosaico, Córdoba, Diputación Provincial.

- (1989): Sonetos como pueblos, Córdoba, Cuadernos de Ulía, Fernán Núñez.

- (1989b): Himnos y texto (Himnos a los árboles; El suicidio de las literaturas), Córdoba, Cultura y Progreso, col. Paralelo 38.

- (1990): La Gorriata, Antequera - Málaga, Luz de la atención.

- (2007): Rojo y sepia, proemio de Antonio Varo Baena, Madrid, Visor.

- (2008): Poesía y sofismas. I. Poesía, ed. Miguel Casado, Madrid, Visor.

- (2010): Poesía y sofismas. II. Sofismas, ed. Miguel Casado, Madrid, Visor.

Ortega y Gasset, José (I9I4): Meditaciones del Quijote, Madrid, Residencia de Estudiantes.

Peralta, Ramón (2005): «El silencio en la poesía», Proyecto patrimonio 2005-letras.s5.com. Página chilena al servicio de la cultura, <http://www.letras.mysite.com/rp041205.htm> (15.06.2018).

Perelman, Chaim y Olbrechts-Tyteca, Lucie (1958): Traité de l'argumentation. La nouvelle rhé- 
torique, Paris, Presses Universitaires de France.

Riera, CARme (I988): La escuela de Barcelona. Barral, Gil de Biedma, Goytisolo: el núcleo poético de la generación de los 50, Barcelona, Anagrama.

Rubio, FANNy (JUlio-Agosto I980): «Teoría y polémica en la poesía española de posguerra», Cuadernos Hispanoamericanos, 36I-362, PP. 192-216.

Searle, John R. (1969): Speech Acts, Cambridge, Cambridge University Press.

Sevillano Calero, Francisco (I998): Propaganda y medios de comunicación en el franquismo, Alicante, Universidad de Alicante, <https://blogs.ua.es/franciscosevillano/files/2012/06/Propaganda-y-medios-de-comunicaci\%25C3\%25B3n.pdf> (15/06/2018).

SPITZER, LeO (I93I): «La interpretación lingüística de las obras literarias», en Kart Vossler, Leo Spitzer y Helmut Hatzfeld, Introducción a la estilística romance, trad. y notas de Amado Alnso y Raimundo Lida, Buenos Aires, Col. de Estudios Estilísticos, pp. 91-148.

Villena, Luis Antonio De (ED.) (2007): El fervor y la melancolía. Los poetas de «Cántico» y su trayectoria, Sevilla, Vandalia - Fundación José Manuel Lara.

- (2009): «Vicente Núñez: esplendor y fracaso de un poética plural», en Celia Fernández Prieto (ed.), Vicente Núñez. Oralista, poeta, sofista, Sevilla, Renacimiento, pp. 33-45. 
